\title{
S100A8 and S100A9 promote endothelial cell activation through the RAGE-mediated mammalian target of rapamycin complex 2 pathway
}

\author{
XIANG ZHONG ${ }^{1 *}$, FENGWEN XIE $^{1 *}$, LI CHEN $^{2}$, ZHIXING LIU ${ }^{2}$ and QUN WANG ${ }^{1}$ \\ Departments of ${ }^{1}$ Cardiac Surgery and ${ }^{2}$ Ultrasound, The First Affiliated Hospital of Nanchang University, \\ Nanchang, Jiangxi 330006, P.R. China
}

Received April 22, 2020; Accepted August 21, 2020

DOI: $10.3892 / \mathrm{mmr} .2020 .11595$

\begin{abstract}
S100 calcium binding protein A8 (S100A8) and A9 (S100A9) belong to the S100 family of calcium-binding proteins and have important roles in inflammation. They increase endothelial cell proliferation, thereby affecting inflammation, angiogenesis and tumorigenesis. However, the mechanism of action of S100A8/9 in endothelial cells needs further study. Therefore, the present study sought to investigate the effects of S100A8/9 on the proliferation and angiogenesis of human umbilical vein endothelial cells (HUVECs) and their mechanism of action. The viability of HUVECs was determined through a Cell Counting Kit-8 assay. The effect of S100A8/9 on the proliferation of HUVECs was detected by flow cytometry. Migration was evaluated by a Transwell migration assay. Apoptosis was evaluated by Annexin V-FITC and PI staining via flow cytometry. Western blot analysis and reverse transcription-quantitative polymerase chain reaction assays were performed to evaluate the activation of the phosphatidylinositol 3-phosphate kinase (PI3K)/Akt/mTOR pathway and mTOR complex 2 (mTORC2). We previously confirmed that S100A8/9 were consistently overexpressed at 1 and 7 days post-surgery in a rabbit vein graft model, which is the period when apoptosis changes to proliferation in neointimal hyperplasia. In the present study, proliferation, viability and migration were increased after treating HUVECs with S100A8/9. S100A8/9 stimulated the PI3K/Akt/mTOR pathway and mTORC2, which was significantly suppressed by a receptor for advanced glycation end
\end{abstract}

Correspondence to: Dr Qun Wang, Department of Cardiac Surgery, The First Affiliated Hospital of Nanchang University, 17 Yong Wai Zheng Street, Nanchang, Jiangxi 330006, P.R. China E-mail: wanqun98054@163.com

*Contributed equally

Key words: S100 protein, endothelial cell, receptor for advanced glycation end products, neointimal hyperplasia, mTOR, mTOR complex 2 products (RAGE)-blocking antibody. Furthermore, depleting expression of RAGE or mTORC2 protein components (rapamycin-insensitive companion of mTOR) by small interfering RNA was found to reduce the cell viability, migration and angiogenesis of S100A8/9-treated HUVECs. The development of neointimal hyperplasia is a complex process initiated by damage to endothelial cells. In conclusion, S100A8/9 has an important role in intimal hyperplasia by promoting cell growth and angiogenesis via RAGE signaling and activation of $\mathrm{mTORC} 2$.

\section{Introduction}

Vein grafts are currently the preferred method for coronary artery bypass grafting (1). However, because of atherosclerosis, atherosclerotic plaque rupture and intimal hyperplasia (2), the 10 -year primary patency rate is only $60 \%$ (3-5). Few interventions are effective in preventing vein graft failure (1). No-touch techniques, antiplatelet (aspirin) therapy and lipid-lowering agents are effective treatments for atherosclerosis, but no intervention is unequivocally clinically effective in intimal hyperplasia, which is the primary reason for vein graft failure (1). Therefore, a novel treatment strategy for intimal hyperplasia is essential for long-term surgical success.

S100 calcium binding protein A8 (S100A8) and A9 (S100A9) belong to the S100 calcium-binding protein family, which is characterized by the presence of two $\mathrm{Ca}^{2+}$-binding sites of the EF-hand type (6). S100A8 and S100A9 normally form a heterodimer called calprotectin that, when secreted, binds receptor for advanced glycation end products (RAGE) $(7,8)$ and Toll-like receptor 4 on different cell types $(9,10)$. In inflammation, $S 100 \mathrm{~A} 8 / 9$ are primarily secreted by neutrophils and induce a broad range of processes, including cellular differentiation, apoptosis, proliferation, migration, calcium homeostasis, energy metabolism and inflammation (11-14). S100A8/9 are increased in a number of cardiovascular diseases. The expression levels of S100A8/9 are increased in coronary artery blood in patients with acute coronary syndrome where they co-localize with leukocytes and are correlated with leukocyte activation (15). This activation induces their adhesion to the endothelium and increases transendothelial migration (16). Serum S100A8/9 expression 
levels are significantly promoted 1 day after percutaneous coronary intervention in patients with acute myocardial infarction (17). As inflammatory molecules, S100A8/9 have an important role in inducing vascular inflammation (18). Previous research revealed that S100A8/9 promoted vessel formation (19). However, endothelial cell injury or exposure of vascular smooth muscle cells to circulating blood components triggers the development of neointimal hyperplasia (1). Venous graft failure after coronary artery bypass graft is caused by the loss of endothelial cell integrity (20).

Extensive studies have focused on the role of S100A8/9 in proinflammation $(9,18,19)$; however, previous findings indicated that a low concentration of S100A8/9 might be associated with cell growth $(21,22)$ and angiogenesis-related activity (19). $\mathrm{Xu}$ et al (21) observed cell proliferation in a concentration- and time-dependent manner with maximal effects observed with $500 \mathrm{ng} / \mathrm{ml}$ S100A9. Li et al (19) demonstrated that following treatment with S100A8 and S100A9, angiogenesis was promoted for endothelial cells; both proteins increased vessel development in gel plugs that were subcutaneously injected in BALB/c mice. These findings indicate that S100A8/9 are associated with endothelial cell growth and angiogenesis, which might protect vein grafts from neointimal hyperplasia. However, the downstream signaling mechanisms are not fully understood, which led the present study to explore their potential mechanisms. The phosphatidylinositol 3-phosphate kinase (PI3K)/Akt/mTOR signaling pathway is a regulator of cell growth, proliferation, metastasis, lipogenesis, angiogenesis and lipogenesis. In the early stage of neointimal hyperplasia, the activation of $\mathrm{PI} 3 \mathrm{~K} / \mathrm{Akt} / \mathrm{mTOR}$ promotes the proliferation of vascular smooth muscle cells and increased extracellular matrix (23). The present study focused on overexpressed S100A8 and S100A9 genes in a vein graft model and used in vitro human umbilical vein endothelial cells (HUVECs) to evaluate the effects of exogenous S100A8/9 on proliferation, migration and angiogenesis, and to explore the signaling pathways involved.

\section{Materials and methods}

Cell culture and viability assay. HUVECs were isolated from umbilical cord veins of normal pregnancies following a previously described protocol (24). The cells were cultured in Endothelial Cell Medium (ScienCell Research Laboratories, Inc.) containing $100 \mathrm{U} / \mathrm{ml}$ penicillin, $100 \mu \mathrm{g} / \mathrm{ml}$ streptomycin and 5\% fetal bovine serum (Gibco; Thermo Fisher Scientific, Inc.) and 1\% vascular Endothelial Cell Growth Factor (ECGF; ScienCell Research Laboratories, Inc.) at $37^{\circ} \mathrm{C}$ with $5 \% \mathrm{CO}_{2}$. HUVECs were pretreated with $10 \mu \mathrm{g} / \mathrm{ml}$ RAGE blocking antibody (cat.no. MAB11451; R\&D Systems) or $100 \mathrm{nM}$ rapamycin for $1 \mathrm{~h}$ prior to treating with S100A8/9 for $48 \mathrm{~h}$ at $37^{\circ} \mathrm{C}$ with $5 \% \mathrm{CO}_{2}$. Cell viability was measured using a Cell Counting Kit-8 (CCK-8) assay (Sigma-Aldrich; Merck KGaA) according to the manufacturer's protocol. Briefly, cells $\left(3 \times 10^{4}\right.$ cells $/ 100 \mu 1$ per well) were plated in 96-well microplates, cultured overnight in complete culture medium, washed and starved in serum-free DMEM (ScienCell Research Laboratories, Inc.) for $6 \mathrm{~h}$. Cells were then treated with S100A8/9 mixture $(0,1$, 2,4 and $8 \mu \mathrm{g} / \mathrm{ml}$ ) in 5\% serum DMEM for 24,48 and $72 \mathrm{~h}$. The mixture contained the same concentration of recombinant low endotoxin-grade human S100A8 and S100A9 (CycLex: Medical \& Biological Laboratories Co., Ltd). A total of $10 \mu 1$ CCK-8 reagent was added to each well and incubated for $1 \mathrm{~h}$ in the dark and absorbance was quantified at $450 \mathrm{~nm}$ using a SpectraMax ${ }^{\circledR} 190$ spectrophotometer (Molecular Devices, LLC).

Cell transfection. RAGE-specific small interfering (si)RNA (si-RAGE) and rapamycin-insensitive companion of mTOR (Rictor)-specific siRNA (si-Rictor) $(25 \mathrm{nM}$, final concentration) were transfected into HUVECs $\left(3 \times 10^{4}\right)$ in 6-well plates using $10 \mathrm{nM}$ Lipofectamine ${ }^{\circledR}$ RNAiMAX Transfection Reagent (Thermo Fisher Scientific, Inc.) for $24 \mathrm{~h}$ at $37^{\circ} \mathrm{C}$, according to the manufacturer's instructions. All gene-specific siRNAs (RAGE and Rictor) and negative controls (cat. no. A06001) were purchased from Suzhou GenePharma Co., Ltd.. After treatment with $8 \mu \mathrm{g} / \mathrm{ml} \mathrm{S100A8/9} \mathrm{for} 24 \mathrm{~h}$, cell proliferation, Transwell assays and vascular tube formation assays were subsequently performed and transfected cells were harvested at $24 \mathrm{~h}$ for reverse transcription-quantitative PCR (RT-qPCR) or western blotting.

Western blotting. RIPA lysis buffer (TransGen Biotech Co., Ltd.) and protease inhibitor cocktail (TransGen Biotech Co., Ltd.) were used to extract total protein from HUVECs. Total protein was quantified using a bicinchoninic acid assay kit (TransGen Biotech Co., Ltd.). Proteins (30 $\mu \mathrm{g}$ protein/lane) were separated via $10 \%$ SDS-PAGE and electroblotted onto polyvinylidene difluoride membranes. Subsequently, the membranes were blocked with TBS containing 5\% non-fat dry milk at $37^{\circ} \mathrm{C}$ for $1 \mathrm{~h}$. Membranes were incubated overnight at $4^{\circ} \mathrm{C}$ with the following antibodies: Anti- $\beta$-actin $(1: 1,000$; Abcam; cat. no. ab6276), anti-phosphorylated (p)-PI3K (1:1,000; Cell Signaling Technology, Inc.; cat. no. 4257) and total (t)-PI3K (1:1,000; Abcam; cat. no. ab40776), anti-p-Akt (1:5,000; Abcam; cat. no. ab81283) and t-Akt (1:1,000; Cell Signaling Technology, Inc.; cat. no. 4691), anti-p-mTOR (1:1,000; Cell Signaling Technology, Inc.; cat. no. 5536) and anti-t-mTOR (1:1,000; Cell Signaling Technology, Inc.; cat. no. 2983), Bcl-2 (1:1,000; Abcam; cat. no. ab32124), Rictor (1:500; Abcam; cat. no. ab104838), anti-protein kinase $\mathrm{C} \alpha$ (PKC $\alpha$; 1:1,000; Abcam; cat. no. 32376) and anti-GAPDH (1:1,000; Abcam; cat. no. ab8245). Membranes were incubated with HRP-conjugated secondary antibodies (cat. nos. ab6721 and ab6728; $1: 3,000 ;$ Abcam) at $37^{\circ} \mathrm{C}$ for $1 \mathrm{~h}$. Finally, the immunoreactive bands were developed using Supersignal West Femto Maximum Sensitivity Substrate (Thermo Fisher Scientific, Inc.). Protein expression levels were semi-quantified using Quantity One software (version 4.6.6; Bio-Rad Laboratories, Inc.).

Flow cytometry. HUVECs were stimulated with $8 \mu \mathrm{g} / \mathrm{ml}$ S100A8/9 for $24 \mathrm{~h}$. After two washes with PBS, harvested cells were fixed with $75 \%$ ice-cold ethanol in $4^{\circ} \mathrm{C}$ for $8 \mathrm{~h}$. HUVECs were incubated with Cell Cycle Staining Kit (Nanjing KeyGen Biotech Co., Ltd.) for $30 \mathrm{~min}$ in the dark according to the manufacturer's instructions. Then, cells were analyzed using a BD FACSCanto ${ }^{\text {TM }}$ II flow cytometer (BD Biosciences). Data were analyzed using FlowJo software (version 7.6.1; Tree Star, Inc.). 
Cell apoptosis. In the present study, the induction of early and late apoptosis was evaluated by Annexin V-FITC and PI staining and flow cytometry. In brief, HUVECs were seeded $\left(1.2 \times 10^{6}\right)$ in 6-well plates and treated as described in the previous sections. After cell serum-starvation, $8 \mu \mathrm{g} / \mathrm{ml}$ S100A8/9 was added into the culture medium and the cells were cultured for another $24 \mathrm{~h}$. Subsequently, the apoptosis of HUVECs was evaluated using an Annexin V-FITC/PI kit (BD Biosciences), according to the manufacturer's protocol. Cells were gently washed with ice-cold PBS by centrifugation $\left(120 \mathrm{x} \mathrm{g}\right.$ for $5 \mathrm{~min}$ at $\left.4^{\circ} \mathrm{C}\right)$, and resuspended in $500 \mu \mathrm{l} 1 \mathrm{X}$ binding buffer supplemented with $5 \mu 1$ Annexin V-FITC and $5 \mu \mathrm{l}$ PI each cell suspension and incubated for $15 \mathrm{~min}$ at room temperature in the dark. The samples were analyzed using a BD FACSCalibur ${ }^{\mathrm{TM}}$ flow cytometer (BD Biosciences) and FlowJo software (version 7.6.1; Tree Star, Inc.).

Transwell migration assay. HUVECs were cultured, transfected with RAGE siRNA (si-RAGE), Rictor siRNA (si-Rictor) or negative controls (NC), and then serum-starved as aforementioned. Transfected cells were harvested by trypsinization. Cells $\left(3 \times 10^{4}\right)$ in DMEM supplemented with 5\% FBS (ScienCell Research Laboratories, Inc.) were seeded into the Transwell insert ( $8 \mu \mathrm{m}$ pore size; Corning, Inc.). DMEM supplemented with 5\% FBS with or without $\mathrm{S} 100 \mathrm{~A} 8 / 9$ protein $(2,4$ or $8 \mu \mathrm{g} / \mathrm{ml})$ was placed in the lower chamber. The Transwell plates were incubated at $37^{\circ} \mathrm{C}$ in $5 \% \mathrm{CO}_{2}$ for $20 \mathrm{~h}$. Non-migrated cells in the top insert were carefully removed using a cotton swab, and the cells that had migrated to the lower surface of the filter were stained with crystal violet dye for $20 \mathrm{~min}$ in room temperature. Images were captured from three random fields per well using a light microscope (magnification, $\mathrm{x} 200$ ). The results are expressed as the number of migrated cells per field.

In vitro vascular tube formation assay. Transfection of cultured cells was performed as aforementioned, with modifications. Microplates (48-well) were coated with $100 \mu 1$ ice-cold growth factor reduced Matrigel (BD Biosciences) at $37^{\circ} \mathrm{C}$ for $1 \mathrm{~h}$. Cells $\left(3 \times 10^{4}\right)$ were plated in each well with media with or without $\mathrm{S} 100 \mathrm{~A} 8 / \mathrm{A} 9$ proteins. The plates were then incubated at $37^{\circ} \mathrm{C}$ in $5 \%$ $\mathrm{CO}_{2}$ for $4 \mathrm{~h}$. Cultures were then photographed in three randomly selected fields using a fluorescence inverted microscope (magnification, x100) and tube-like structures were evaluated using ImageJ software (version 1.49; National Institutes of Health).

$R T-q P C R$. HUVECs were adjusted to a density of $1 \times 10^{5}$ cells per $\mathrm{cm}^{2}$ in culture media and incubated with S100A8/9 for $24 \mathrm{~h}$. Total RNA was then extracted from the cells using TRIzol ${ }^{\circledR}$ (Beijing Transgen Biotech Co., Ltd.). Single-stranded complementary DNA was synthesized from total RNA by reverse transcription using the PrimeScript RT Reagent kit (Takara Bio, Inc.). RT-qPCR was performed using SYBR-Green master mix (Takara Bio, Inc.) in 96-well reaction plates using the ABI StepOnePlus ${ }^{\mathrm{TM}}$ Real-Time PCR system (Thermo Fisher Scientific, Inc.). Optimal reaction conditions for amplification of the target genes were used according to the manufacturer's recommendations. $\beta$-actin was used as an internal control. Each experiment was performed in duplicate and repeated independently at least three times. Expression levels were quantified using the $2^{-\Delta \Delta \mathrm{Cq}}$ method (25). The primers used for RT-qPCR are presented in Table I.
Table I. Primers used for reverse transcription-quantitative PCR.

\begin{tabular}{ll}
\hline Gene & \multicolumn{1}{c}{ Sequence $\left(5^{\prime} \rightarrow 3^{\prime}\right)$} \\
\hline$\beta$-actin & F: TCACCAACTGGGACGACAT \\
& R: GCACAGCCTGGATAGCAAC \\
Bcl-2 & F: CCGTGGAATGGAATGAGAT \\
& R: TGGTCAAACTTGTTGTCCC \\
Rictor & F: CTGGAAATTCTGGGATACAGTCTCT \\
& R: GGGCTTCTATGAACTCATCCGT
\end{tabular}

F, forward; R, reverse; Rictor, rapamycin-insensitive companion of mTOR.

Microarray and bioinformatics analyses of gene expression. Gene expression data from our previous study of rabbit vein grafts was used (26). Briefly, New Zealand white rabbits $(2.5-3.0 \mathrm{~kg})$ were subjected to the induction of anesthesia with $3 \%$ sodium pentobarbital solution $(30 \mathrm{mg} / \mathrm{kg})$. Rabbits underwent unilateral jugular vein into common carotid artery interposition grafting. This procedure involved $2 \mathrm{~cm}$ segments of jugular vein being harvested using a no-touch method. Segments were stored in an iso-osmotic sodium chloride solution $(0.9 \mathrm{~g} / \mathrm{l})$ containing $2 \mathrm{IU} / \mathrm{ml}$ of heparin and $50 \mu \mathrm{g} / \mathrm{ml}$ of glyceryl trinitrate at $23^{\circ} \mathrm{C}$ until needed. Animals were sacrificed with an overdose of sodium pentobarbital solution $(900 \mathrm{mg} / \mathrm{kg})$, cardiac and respiratory arrest as a mark of animal death. A total of six samples were selected from each of the peaks of apoptosis (day 1) and the peak of PCNA proliferation (day 7) and four samples from normal veins (Control group). Total RNA from each sample was quantified using the NanoDrop ND-1,000 system (NanoDrop Technologies; Thermo Fisher Scientific, Inc.). RNA integrity was assessed using standard electrophoresis on a denaturing agarose gel. Sample labelling and array hybridization were carried out according to the protocol provided by a One-color Microarray-based Gene Expression Analysis kit by Agilent Technologies, Inc. A bioinformatics analysis of the gene expression data was performed. All the animal experiments were carried out according to ethical principles and protocols approved by Medical Ethical Committee of The First Affiliated Hospital of Nanchang University.

Statistical analysis. The data are presented as means \pm standard deviation from at least three independent experiments. Significant between-group differences were analyzed by one-way analysis of variance followed by a Tukey's post hoc test. The analyses were performed with SPSS version 22.0 software (IBM Corp.). $\mathrm{P}<0.05$ was considered to indicate a statistically significant difference.

\section{Results}

S100A8 and S100A9 expression is upregulated in a rabbit vein graft model. A total of 1 day after surgery, cell apoptosis reached a peak and cell proliferation reached a peak 7 days after surgery (26). To discover the potential genes in vein grafts 
whose upregulation was dysregulated during environmental rehabilitation in arteries, these two time points were selected to analyze differential gene expression in the experimental vessel wall relative to the control group. As shown in Fig. 1, S100A8 and S100A9 were significantly upregulated genes among the differentially expressed genes compared with the control group.

S100A8 and S100A9 promote HUVEC viability, proliferation and migration. To investigate the influence of $S 100 \mathrm{~A} 8 / 9$ on cell viability, HUVECs were starved in serum-free DMEM for $6 \mathrm{~h}$ before treatment with S100A8/9 at different times. As shown in Fig. 2A, S100A8/9 exerted a distinct effect on HUVECs. When S100A8/9 was added to culture media at 1, 2, 4 and $8 \mu \mathrm{g} / \mathrm{ml}$, it increased HUVEC viability in dose-dependent and time-dependent manners. The greatest effects were observed with $8 \mu \mathrm{g} / \mathrm{ml}$ at $72 \mathrm{~h}$. As the cell cycle distribution is directly connected to proliferation, the present study further investigated the cell cycle distribution of HUVECs incubated with S100A8/9. As shown in Fig. 2B, the S100A8/9 group displayed the following distribution: $\mathrm{G}_{0} / \mathrm{G}_{1}$ phase, $44.76 \pm 1.10 \% ; \mathrm{S}$ phase, $40.10 \pm 0.73 \% ; \mathrm{G}_{2} / \mathrm{M}$ phase, $15.14 \pm 1.59 \%$. The control group displayed the following distribution: $\mathrm{G}_{0} / \mathrm{G}_{1}$ phase, $59.13 \pm 1.52 \% ; \mathrm{S}$ phase, $27.16 \pm 5.31 \% ; \mathrm{G}_{2} / \mathrm{M}$ phase, $13.70 \pm 4.12 \%$. The results showed that $S 100 A 8 / 9$ increased the $G_{1}$ phase cells to enter the $\mathrm{S}$ phase, thereby improving the cell proliferation ability. Furthermore, the effects of S100A8/9 on HUVEC apoptosis were detected using flow cytometry. After treatment with $8 \mu \mathrm{g} / \mathrm{ml} \mathrm{S100A8/9} \mathrm{for} 24 \mathrm{~h}$, the cell apoptosis rate was significantly decreased from $7.39 \pm 1.23$ to $4.17 \pm 0.89(\mathrm{P}<0.05$; Fig. 2C). Next, the effects of S100A8/9 on migration were evaluated using a Transwell chamber system. As shown in Fig. 2D, DMEM with S100A8/9 at 2, 4 and $8 \mu \mathrm{g} / \mathrm{ml}$ in the lower chamber stimulated cell migration and maximal effects were observed with $8 \mu \mathrm{g} / \mathrm{ml} \mathrm{S100A8/9}$. These results indicated that a S100A8/9 promoted cell viability and migration.

S100A8 and S100A9 stimulate the PI3K/Akt/mTOR signaling pathway. It was previously demonstrated, in an experimental rabbit vein graft model, that the mTOR signaling pathway was upregulated 1 and 7 days after transplantation, when the vein was in the arterialization process (26). It was hypothesized that this could be the mechanism leading to remodeling in the vessel wall. To explore the pathway involved in the effect of S100A8/9 on HUVECs, HUVECs were cultured with $0.5-5 \mu \mathrm{g} / \mathrm{ml} \mathrm{S100A8/9}$ for $48 \mathrm{~h}$. Western blot assays (Fig. 3A) showed that the PI3K/Akt/mTOR pathway was activated, as indicated by the increased expression ratios of $\mathrm{p}-\mathrm{PI} 3 \mathrm{~K} / \mathrm{t}-\mathrm{PI} 3 \mathrm{~K}$, $\mathrm{p}-\mathrm{Akt} / \mathrm{t}-\mathrm{Akt}$ and $\mathrm{p}-\mathrm{mTOR} / \mathrm{t}-\mathrm{mTOR}$. The Akt signaling pathway regulates $\mathrm{Bcl}-2$, which is an important anti-apoptotic protein, therefore, the expression levels of Bcl-2 protein and mRNA were determined. As shown in Fig. 3C, S100A8/9 promoted the expression of Bcl-2 mRNA and protein. $\mathrm{mTOR}$ is involved in two distinct multi-protein complexes, mTORC1/2. mTORC2 contains mTOR, target of rapamycin complex subunit LST8, Rictor, target of rapamycin complex 2 subunit MAPKAP1, proline-rich protein 5 and DEP domain containing mTOR-interacting protein, and regulates Akt and PKC $\alpha$ phosphorylation and actin cytoskeleton formation $(27,28)$. The expression of Rictor was examined to determine whether

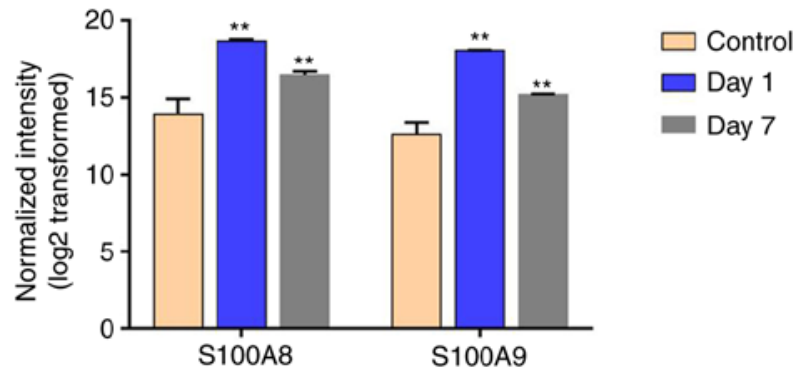

Figure 1. Altered expression levels of S100A8 and S100A9. The expression levels of S100A8 and S100A9 were detected at 0, 1 and 7 days after surgery. Sample labelling and array hybridization were carried out according to the protocol provided by a One-color Microarray-based Gene Expression Analysis kit (Agilent Technologies, Inc.). Data and error bars represent the mean \pm SEM $(n=6) .{ }^{* *} \mathrm{P}<0.01$ vs. control group. S100A, S100 calcium binding protein A.

mTORC2 was activated. S100A8/9 significantly upregulated Rictor, similarly to its downstream factor PKC $\alpha$ (Fig. 3B). This suggested that PI3K/Akt/mTOR and mTORC2 signaling pathways may participate in S100A8/9-induced HUVEC activation.

Effects of RAGE blockade on S100A8/9 stimulation of the PI3K/Akt/mTOR and mTORC2 signaling pathways. RAGE is a primary extracellular-membrane receptor of S100 proteins. Therefore, the influence of RAGE was investigated on the S100A8/9 signaling pathway, HUVECs were pretreated with a RAGE blocking antibody or the mTOR inhibitor, $100 \mathrm{nM}$ rapamycin. Fig. 4A shows that the RAGE blocking antibody decreased the expression ratios of $\mathrm{p}-\mathrm{PI} 3 \mathrm{~K} / \mathrm{t}-\mathrm{PI} 3 \mathrm{~K}$, $\mathrm{p}$-Akt/t-Akt and p-mTOR/t-mTOR. Rapamycin also decreased the expression ratios of $\mathrm{p}-\mathrm{mTOR} / \mathrm{t}-\mathrm{mTOR}$ induced by S100A8/9, similarly to the RAGE blocking antibody. As a main component of mTORC2, Rictor protein expression was determined. As shown in Fig. 4B, at the protein level, only the RAGE blocking antibody inhibited expression of Rictor and PKC $\alpha$. At the mRNA expression level, Rictor expression was decreased when cells were pretreated with a RAGE blocking antibody before stimulation with S100A8/9 (Fig. 4C). Therefore, RAGE appears to be a candidate receptor not only of the PI3K/Akt/mTOR signaling pathway but also mTORC2 signaling in HUVECs.

Effect of RAGE and mTORC2 on S100A8/9-stimulation of angiogenesis and cell migration. MTORC2 is essential for VEGF-induced angiogenic responses, whereas mTORC1 is known to have a relatively modest effect on vascular endothelial cell function (29). In addition, PKC $\alpha$, a distinct signaling protein downstream of $\mathrm{mTORC} 2$, is required for proliferation of vascular endothelial cells (30). To further demonstrate the role of RAGE and mTORC2 in S100A8/9 stimulation, a CCK-8 assay was performed to measure cell viability. HUVECs were transfected with siRNAs targeting the expression of Rictor or RAGE or a negative control siRNA. First, transfection efficiency of si-Rictor and si-RAGE was determined (Fig. 5A and B). Reduction of Rictor or RAGE expression decreased the viability of S100A8/9-treated cells by similar amounts (Fig. 5C). Then, HUVEC migration (Fig. 5D) and 


\section{A}
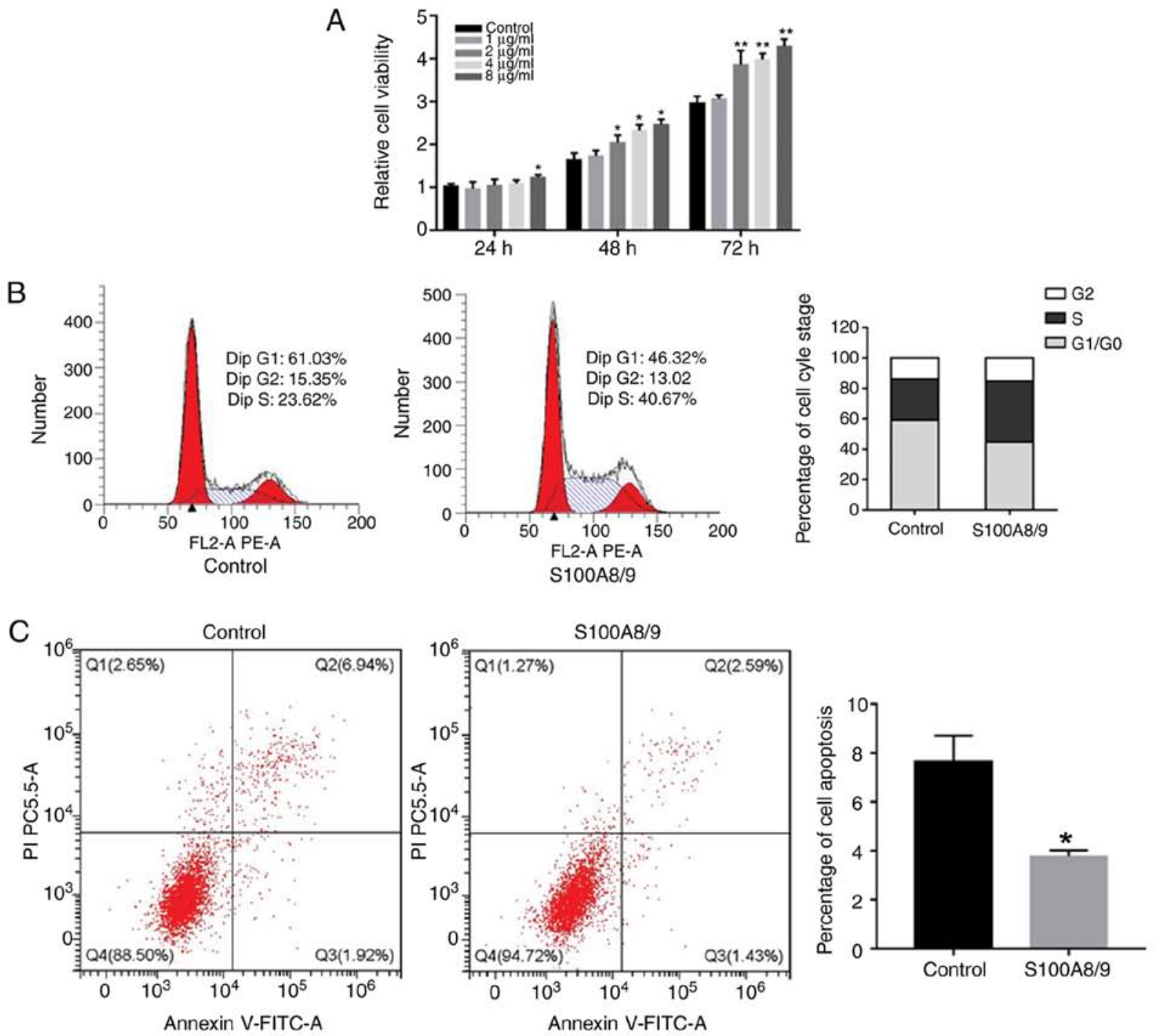

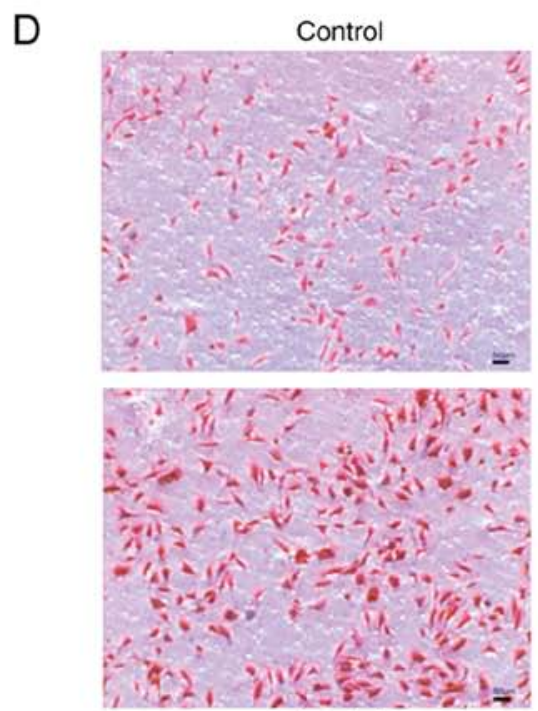

$4 \mu \mathrm{g} / \mathrm{ml}$
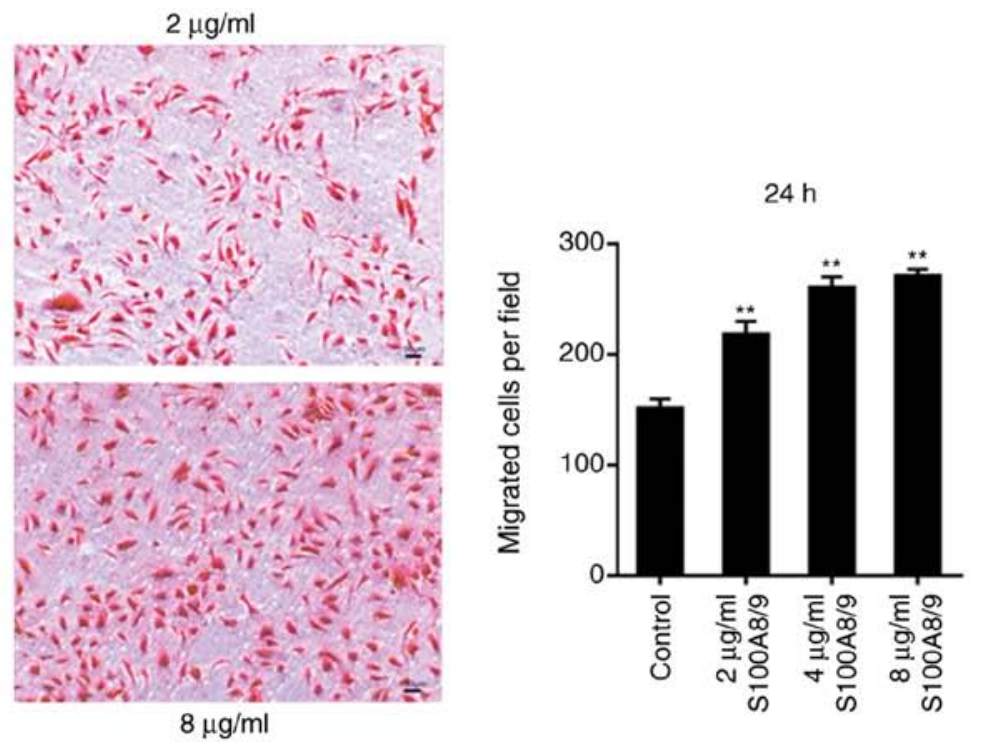

Figure 2. Effects of S100A8/9 on viability and migration of HUVECs. (A) Cells were plated at an equal density and treated with various concentrations of S100A8/9 $(1-8 \mu \mathrm{g} / \mathrm{ml})$ or an equal volume of PBS for 24-96 h, and viability was assessed by Cell Counting Kit-8 assays. The relative ratios of cell viability are expressed as a percentage of the $24 \mathrm{~h}$ control group. Data and error bars represent the mean \pm SEM (n=3). (B) Flow cytometry analysis for the cell cycle distribution of HUVECs incubated with S100A8/9 for $24 \mathrm{~h}$ or control group, and (C) flow cytometry analysis for the cell apoptosis of HUVECs incubated with S100A8/9 for $24 \mathrm{~h}$ or control group. (D) Transwell migration assays showed significantly increased migration of HUVECs under various concentrations of S100A8/9 $(2-8 \mu \mathrm{g} / \mathrm{ml})$ compared with PBS control. Images were captured (original magnification, $\mathrm{x} 200)$ of HUVECs migrated through Transwell chambers. Data and error bars represent the mean $\pm \operatorname{SEM}(\mathrm{n}=3) .{ }^{*} \mathrm{P}<0.05,{ }^{* *} \mathrm{P}<0.01$ vs. control group. HUVECs, human umbilical vein endothelial cell; S100A, S100 calcium binding protein $\mathrm{A}$. 
A
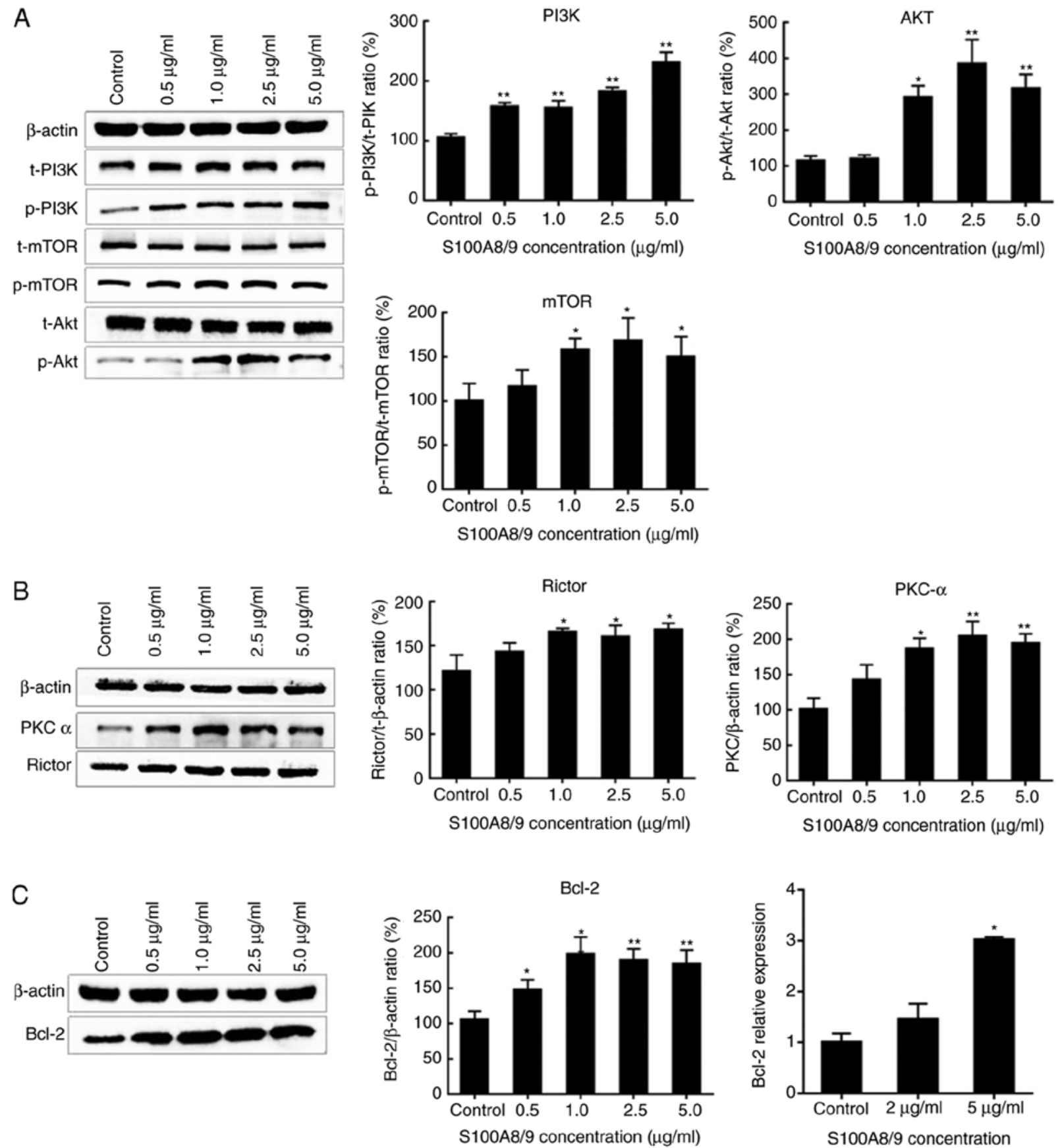

Figure 3. S100A8/9 stimulates the PI3K/Akt/mTOR pathway, Bcl-2 and Rictor in HUVECs. (A) S100A8/9 administration stimulates the PI3K/Akt/mTOR pathway by increasing the expression ratios of p-PI3K/t-PI3K, p-Akt/t-Akt and p-mTOR/t-mTOR. (B) The changes in Rictor and PKC $\alpha$ expression were detected by western blotting. (C) S100A8/9 increased protein and mRNA expression of Bcl-2. Data and error bars represent the mean \pm SEM ( $n=3$ ). ${ }^{*} \mathrm{P}<0.05$, ${ }^{* *} \mathrm{P}<0.01$ vs. control group. HUVECs, human umbilical vein endothelial cell; S100A, S100 calcium binding protein A; Rictor, rapamycin-insensitive companion of mTOR; PKC $\alpha$, protein kinase $\mathrm{C} \alpha$; p-, phosphorylated; t-, total.

angiogenesis (Fig. 5E) were measured. As expected, S100A8/9 increased angiogenesis, whereas depletion of RAGE and Rictor produced the opposite result (Fig. 5E). Similarly, the increase in migration was abrogated upon depletion of RAGE or Rictor (Fig. 5D); however, the results were not significant.

\section{Discussion}

In the present study, S100A8/9 was found to enhance cell growth and angiogenesis. Inhibition of RAGE with si-RAGE decreased HUVEC viability and migration. S100A8/9 stimulated the mTORC2 pathway, which was significantly suppressed by rapamycin and a RAGE-blocking antibody; Rictor deficiency partly reduced cell viability and angiogenesis induced by S100A8/9.

Recently, the failure of vein grafts induced by neointimal hyperplasia has attracted attention in research (5). Neointimal hyperplasia is an exaggerated wound-healing process in the vessel wall resulting from surgical injury, arterial environment changes or inflammation post-surgery (1). It is initiated by injury to vascular endothelial cells and exposure of vascular smooth muscle cells to circulating blood molecules (23). 

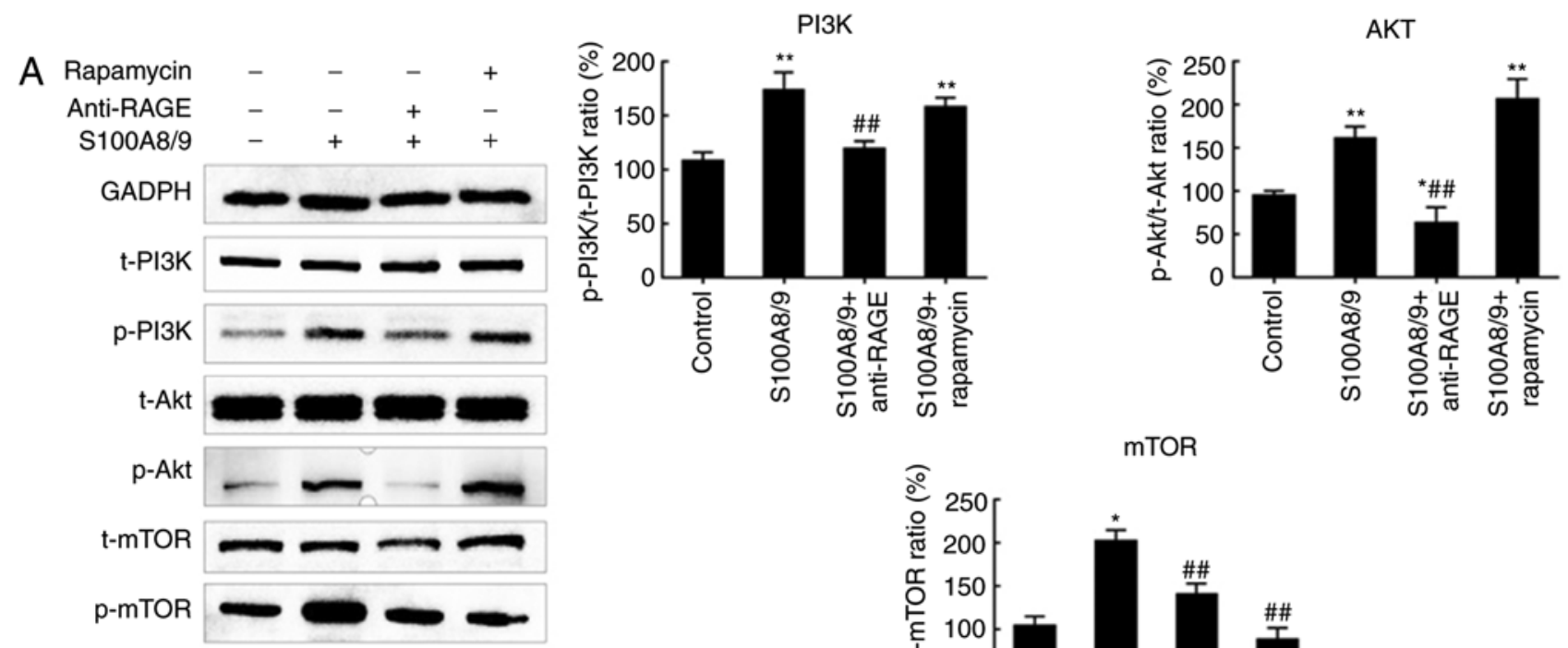

mTOR
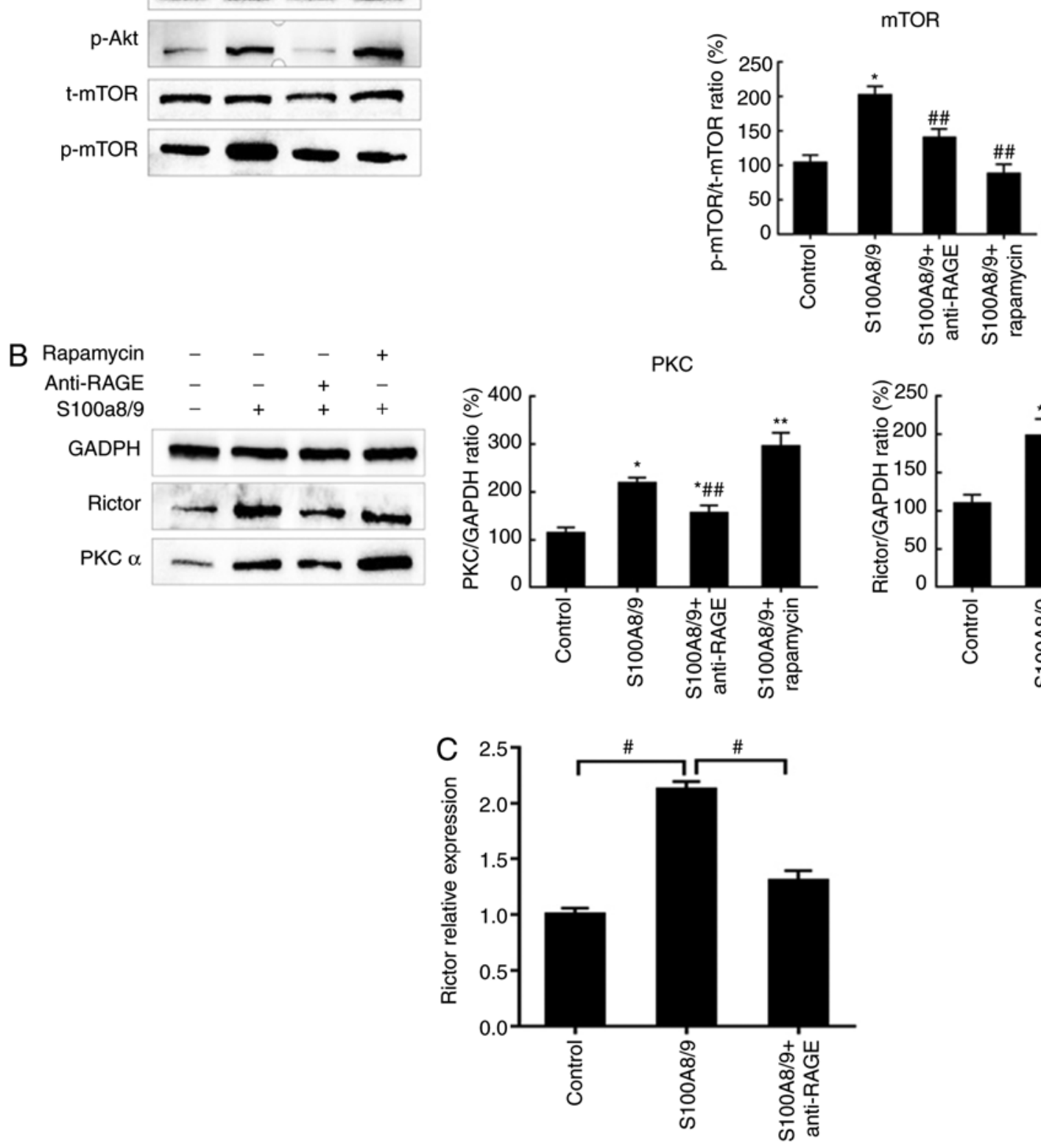

Figure 4. S100A8/9-induced HUVEC activation is RAGE-dependent. HUVECs were pretreated with $10 \mu \mathrm{g} / \mathrm{ml}$ RAGE blocking antibody or $100 \mathrm{nM}$ rapamycin for $1 \mathrm{~h}$ prior to treating with S100A8/9 for $48 \mathrm{~h}$. Total protein was harvested and subjected to western blotting. (A) RAGE antibody pretreatment blocked the $\mathrm{PI} 3 \mathrm{~K} / \mathrm{Akt} / \mathrm{mTOR}$ pathway, whereas rapamycin only reduced mTOR phosphorylation. (B) RAGE antibody pretreatment blocked Rictor and PKC $\alpha$, whereas rapamycin made no difference. (C) The change in Rictor mRNA expression was measured by reverse transcription-quantitative PCR. Data and error bars represent the mean \pm SEM $(\mathrm{n}=3) .{ }^{*} \mathrm{P}<0.05,{ }^{* *} \mathrm{P}<0.01$ vs. control group; ${ }^{*} \mathrm{P}<0.05,{ }^{\# /} \mathrm{P}<0.01$ vs. S100A8/9 group. RAGE, receptor for advanced glycation end products; S100A, S100 calcium binding protein A; Rictor, rapamycin-insensitive companion of mTOR; PKC $\alpha$, protein kinase C $\alpha$; p-, phosphorylated; t-, total.

A study indicated that reendothelialization is beneficial to prevent the failure of vein transplantation, but so far there is no treatment to promote this process (20). Our previous studies demonstrated that, in the rabbit vein transplant model, a high level of cell proliferation was observed in the vascular wall of vein graft on day 7 after surgery (26). The present study found that S100A8 and S100A9 genes in vein grafts were upregulated during environmental rehabilitation in arteries 
A

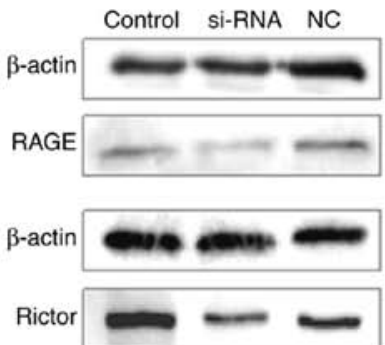

B

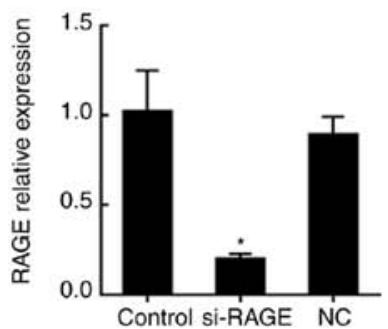

D
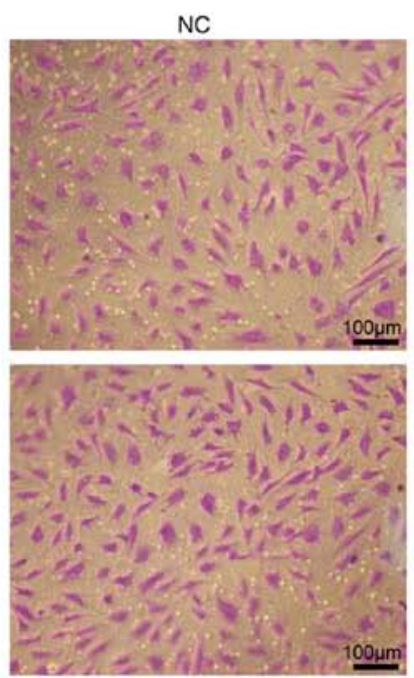

S100A8/9+RAGE

E
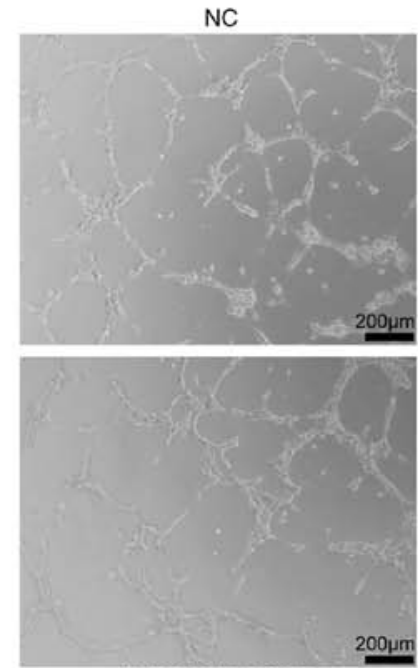

S100A8/9+RAGE
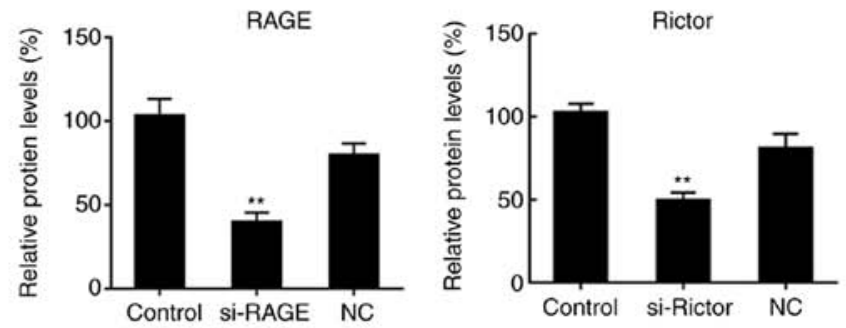

$48 \mathrm{~h}$
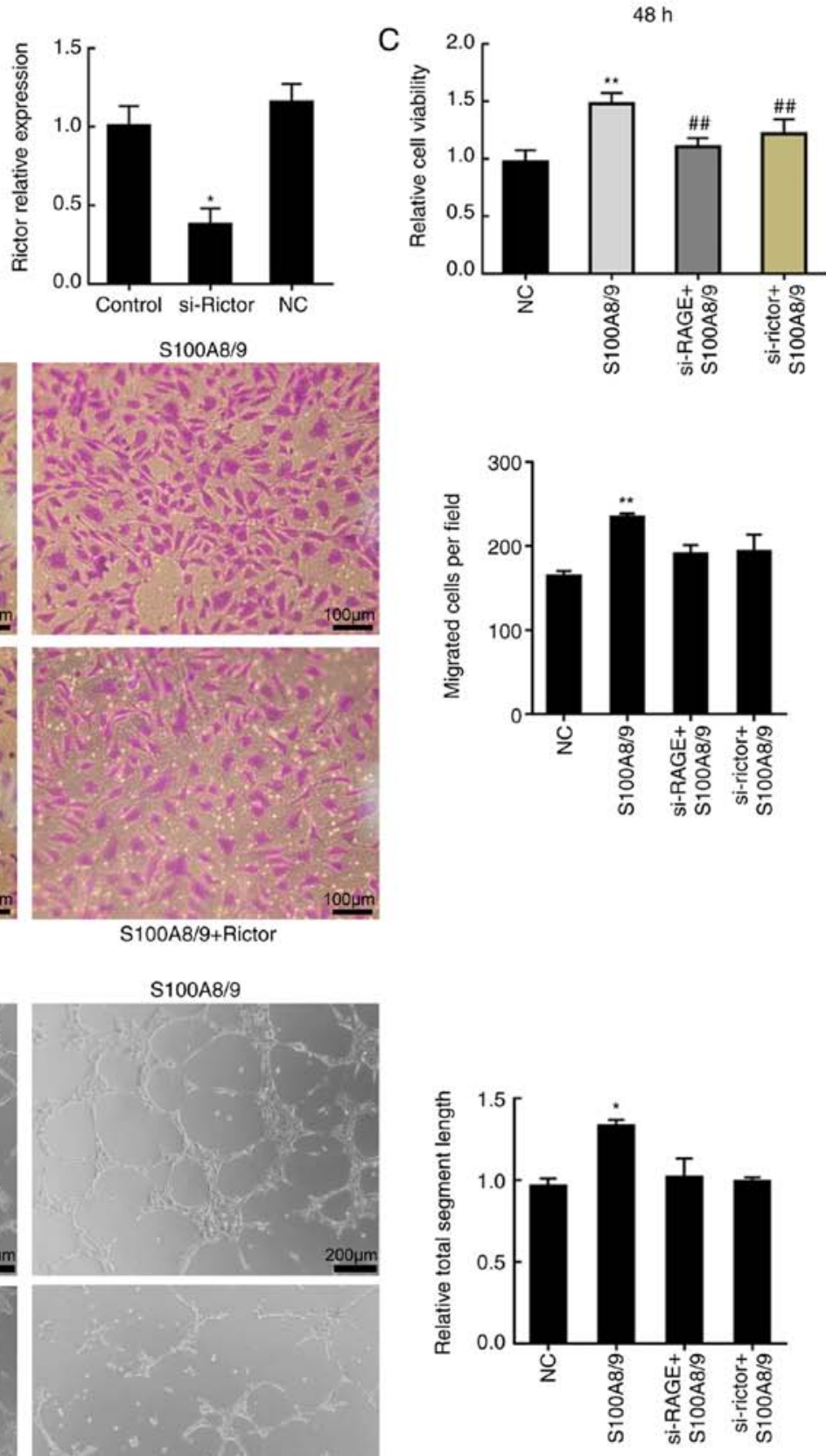

Figure 5. Effects of RAGE blockade on S100A8/9 stimulation of the PI3K/Akt/mTOR and mTORC2 signaling pathways. (A) Human umbilical vein endothelial cells transfected with si-RAGE, si-Rictor or control, as indicated, were subjected to serum starvation for 24 h. Total protein was harvested and subjected to western blotting. (B) Total RNA was harvested and subjected to reverse transcription-quantitative PCR. (C) Viability was assessed by Cell Counting Kit- 8 assays. The relative cell viability ratios are expressed as a percentage of the $48 \mathrm{~h}$ control group. (D) RAGE and Rictor knockdown by siRNA can partially reverse the S100A8/9-induced increase in cell migration. (E) RAGE and Rictor knockdown by siRNA can partially prevent the S100A8/9-induced angiogenesis. Data and error bars represent the mean \pm SEM $(n=3) .{ }^{*} \mathrm{P}<0.05,{ }^{* *} \mathrm{P}<0.01$ vs. control group; ${ }^{\# \#} \mathrm{P}<0.01 \mathrm{vs}$. S100A8/9 group. RAGE, receptor for advanced glycation end products; S100A, S100 calcium binding protein A; Rictor, rapamycin-insensitive companion of mTOR; siRNA, small interfering RNA; NC, negative control. 
7 days after surgery, when a high level of cell proliferation is observed in the vascular wall of vein grafts. At present, primary umbilical vein endothelial cells are widely used in experiments to explore the function of venous endothelial cells (31). Therefore, umbilical vein endothelial cells were selected as the research subject in the present study. In vitro, the promotion of proliferation and angiogenesis was observed with S100A8/9 treatment. These results were consistent with those of Li et al (19) who showed that low concentrations of S100A8 and S100A9, either alone or in combination, promoted angiogenesis-related activity in vascular endothelial cells. This evidence confirmed the proliferative function of S100A8/9 on endothelial cells. It was further speculated that, in preventing neointimal hyperplasia, S100A8/9 maintained the endothelial integrity of vein grafts, which protected vascular smooth muscle cells from circulating blood inflammatory molecules.

PI3K/Akt signaling has a key role in multiple cellular processes, such as promotion of survival and growth in response to extracellular signals. Activated Akt mediates downstream responses, including cell survival, growth, proliferation, cell migration and angiogenesis (16), by phosphorylating a range of intracellular proteins, which includes mTOR. mTOR links with other proteins and serves as a core component of two distinct protein complexes, mTORC21 and $\mathrm{mTORC} 2$, which regulate different cellular processes (32). In the rabbit vein grafts model, mTORC2 function was increased in the week after surgery and remained upregulated (26), which could be a major reason behind the formation of neointimal hyperplasia. In the present study, S100A8 and S100A9 genes were found to be overexpressed. In vitro experiments showed that PI3K/Akt/mTOR and mTORC2 pathways were activated by S100A8/9. This result was consistent with our previous animal experimental model data (26), which indicated that mTORC2 signaling pathways are activated by S100A8/9. Depleting the core molecule Rictor from the mTORC2 complex, attenuated the cell proliferation caused by S100A8/9. These results further indicated that S100A8/9 promoted cell proliferation, migration and angiogenesis via the mTORC2 signaling pathway. Considering this evidence, it was speculated that S100A8/9 protects the integrity of endothelial cells through mTORC2 signaling pathways.

The present study also investigated the role of RAGE in S100A8/9-stimulated activation of the mTORC2 pathway and promotion of angiogenesis. The multi-ligand receptor, RAGE is a strong candidate for several pathways mediating arterial inflammation (33). RAGE ligands include advanced glycation end products, high mobility group box 1 and S100/calgranulins, which includes S10012, S100A8 and S100A9 (34,35). It has been demonstrated that S100A8/9 interacts with RAGE in HUVECs (36,37). Furthermore, RAGE regulates the phosphorylation of mTOR and promotes Beclin-1/VPS34 autophagosome formation (38). Advanced glycation end products induce cell autophagy by inhibiting the PI3K/Akt/mTOR pathway via RAGE $(39,40)$. The signaling pathway of RAGE in endothelial cells has not yet been fully elucidated. The present results showed that the RAGE blocking antibody reduced activation of the S100A8/9-upregulated mTORC2 pathway, whereas Rapamycin had little effect; RAGE deficiency partly reversed the promotion of angiogenesis. These results provided evidence that RAGE is the receptor for S100A8/9, and that RAGE-dependent signaling is involved in mediating the effects of S100A8/9, which is consistent with the findings of Xu et al (21).

A previous study demonstrated that hypoxia causes a transient increase in mTORC1 activity and a sustained increase in mTORC2 activity in vascular endothelial cells, which indicates that proliferation in vascular endothelium is correlated with mTORC2 activity (41). The knockout regulatory-associated protein of mTOR (Raptor)/Rictor gene mouse model demonstrated that absence of Rictor inhibited endothelial cell proliferation and angiogenesis induced by VEGF in vivo, which could be achieved by decreasing downstream factor-PKC $\alpha$, whereas Raptor knockout had little effect on vascular endothelial cells (29). Previous evidence suggested that the chemokine stromal cell-derived factor 1 , through its receptor C-X-C chemokine receptor type 4 , increased endothelial cell migration and microangiogenesis to promote angiogenesis (27). To block angiogenesis, mTORC2 signaling is the correct blocking target, rather than mTORC1 (27), however, while rapamycin is a potent inhibitor of $\mathrm{mTORC} 1, \mathrm{mTORC} 2$ is only partially affected after long-term exposure (42). The present results showed that rapamycin failed to decrease activation of mTORC2 stimulated by S100A8/9, whereas RAGE had a notable effect on the inhibition of mTORC2 stimulation. These findings indicated that RAGE could be a potential target in the mTORC2 pathway.

There are some limitations of the present study. No clinical evidence has been presented concerning the relationship between serum expression levels of S100A8/9 and intimal hyperplasia after vein graft surgery in patients with coronary atherosclerosis. The results of this study may not be directly applicable to neointimal hyperplasia in an in vivo coronary artery bypass grafting model because the findings in this study are from a HUVEC in vitro model only. Therefore, a new human-mouse chimeric model based on human-mouse chimeric model reported by Yi et al (43) is in development. In future studies, human saphenous vein segments should be transplanted as abdominal aorta interposition grafts into an immunodeficient mouse host. In addition, the present study did not investigate the interaction between the PI3K/Akt/mTOR signaling pathway and mTORC2. Although, no time-dependent activity of S100A8/9 was provided for PI3K/Akt/mTOR, the potential mechanisms underlying the effects of S100A8/9 on promoting cell viability were investigated. Furthermore, while the western blotting results (Fig. 3A) may not be optimal, they are sufficient to draw the conclusion that S100A8/9 stimulates activation of the PI3K/Akt/mTOR pathway.

In summary, S100A8/9 promoted cell viability, proliferation and migration via RAGE signaling and activation of mTORC2 pathways. S100A8 and S100A9 genes in vein grafts were upregulated in a rabbit vein grafts model. Thus, it was speculated that S100A8/9 protected the endothelial integrity of vein grafts, which play an important role in preventing intimal hyperplasia (20). In addition, RAGE could represent a potential target in the mTORC2 pathway. The present study therefore offers a preliminary understanding of the potential role of S100A8/9 in intimal hyperplasia in vein graft surgery. Further studies are required to fully understand the role of S100A8/9 in the pathogenesis of intimal hyperplasia, and vascular smooth muscle cells are an ideal tool for this so these cells will be used for future studies. 


\section{Acknowledgements}

Not applicable.

\section{Funding}

This work was supported by the National Natural Science Foundation of China (grant no. 81760078) and Jiangxi Provincial Natural Science Foundation of China (grant no. 20192ACBL21039).

\section{Availability of data and materials}

The datasets used and/or analyzed during the current study are available from the corresponding author on reasonable request.

\section{Authors' contributions}

$\mathrm{XZ}$ performed the experiments. FX, LC and ZL analyzed the data and revised the manuscript. FX collected data and wrote the manuscript. QW conceived and designed the experiments. All authors read and approved the final manuscript.

\section{Ethics approval and consent to participate}

The present study was approved by the Medical Ethical Committee of The First Affiliated Hospital of Nanchang University.

\section{Patient consent for publication}

Not applicable.

\section{Competing interests}

The authors declare that they have no competing interests.

\section{References}

1. de Vries MR, Simons KH, Jukema JW, Braun J and Quax PH: Vein graft failure: From pathophysiology to clinical outcomes. Nat Rev Cardiol 13: 451-470, 2016.

2. Owens CD: Adaptive changes in autogenous vein grafts for arterial reconstruction: Clinical implications. J Vasc Surg 51: 736-746, 2010

3. Gasper WJ, Owens CD, Kim JM, Hills N, Belkin M, Creager MA and Conte MS: Thirty-day vein remodeling is predictive of midterm graft patency after lower extremity bypass. J Vasc Surg 57: 9-18, 2013

4. Conte MS, Owens CD, Belkin M, Creager MA, Edwards KL, Gasper WJ, Kenagy RD, LeBoeuf RC, Sobel M and Clowes A: A single nucleotide polymorphism in the p27(Kip1) gene is associated with primary patency of lower extremity vein bypass grafts. J Vasc Surg 57: 1179-1185.e1-e2, 2013.

5. Lu DY, Chen EY, Wong DJ, Yamamoto K, Protack CD, Williams WT, Assi R, Hall MR, Sadaghianloo N and Dardik A: Vein graft adaptation and fistula maturation in the arterial environment. J Surg Res 188: 162-173, 2014.

6. Hunter MJ and Chazin WJ: High level expression and dimer characterization of the S100 EF-hand proteins, migration inhibitory factor-related proteins 8 and 14. J Biol Chem 273: 12427-12435, 1998.

7. Boyd JH, Kan B, Roberts H, Wang Y and Walley KR: S100A8 and S100A9 mediate endotoxin-induced cardiomyocyte dysfunction via the receptor for advanced glycation end products. Circ Res 102: 1239-1246, 2008.
8. Chang CC, Khan I, Tsai KL, Li H, Yang LW, Chou RH and Yu C: Blocking the interaction between S100A9 and RAGE V domain using CHAPS molecule: A novel route to drug development against cell proliferation. Biochim Biophys Acta 1864: 1558-1569, 2016

9. Averill MM, Kerkhoff C and Bornfeldt KE: S100A8 and S100A9 in cardiovascular biology and disease. Arterioscler Thromb Vasc Biol 32: 223-229, 2012.

10. Vogl T, Propper C, Hartmann M, Strey A, Strupat K, van den Bos C, Sorg C and Roth J: S100A12 is expressed exclusively by granulocytes and acts independently from MRP8 and MRP14. J Biol Chem 274: 25291-25296, 1999.

11. Marenholz I, Heizmann CW and Fritz G: S100 proteins in mouse and man: From evolution to function and pathology (including an update of the nomenclature). Biochem Biophys Res Commun 322: 1111-1122, 2004.

12. Leclerc E, Fritz G, Vetter SW and Heizmann CW: Binding of S100 proteins to RAGE: An update. Biochim Biophys Acta 1793: 993-1007, 2009.

13. Donato R, Cannon BR, Sorci G, Riuzzi F, Hsu K, Weber DJ and Geczy CL: Functions of S100 proteins. Curr Mol Med 13: 24-57, 2013.

14. Gross SR, Sin CG, Barraclough R and Rudland PS: Joining S100 proteins and migration: For better or for worse, in sickness and in health. Cell Mol Life Sci 71: 1551-1579, 2014.

15. Buyukterzi Z, Can U, Alpaydin S, Guzelant A, Karaarslan S, Kocyigit D and Gurses KM: Enhanced S100A9 and S100A12 expression in acute coronary syndrome. Biomark Med 11: 229-237, 2017.

16. Wang S, Song R, Wang Z, Jing Z, Wang S and Ma J: S100A8/A9 in Inflammation. Front Immunol 9: 1298, 2018.

17. Li Y, Chen B, Yang X, Zhang C, Jiao Y, Li P, Liu Y, Li Z, Qiao B, Bond Lau W, et al: S100a8/a9 signaling causes mitochondrial dysfunction and cardiomyocyte death in response to ischemic/reperfusion injury. Circulation 140: 751-764, 2019.

18. Stocca A, O'Toole D, Hynes N, Hynes SO, Mashayekhi K, McGinley L, O'Connell E, Coleman C, Sultan S, Duffy A, et al: A role for MRP8 in in stent restenosis in diabetes. Atherosclerosis 221: 325-332, 2012.

19. Li C, Li S, Jia C, Yang L, Song Z and Wang Y: Low concentration of S100A8/9 promotes angiogenesis-related activity of vascular endothelial cells: Bridges among inflammation, angiogenesis, and tumorigenesis? Mediators Inflamm 2012: 248574, 2012.

20. Ben Ali W, Bouhout I and Perrault LP: The effect of storage solutions, gene therapy, and antiproliferative agents on endothelial function and saphenous vein graft patency. J Card Surg 33: 235-242, 2018

21. XuX, Chen H,Zhu X, Ma Y,Liu Q, Xue Y, Chu H,Wu W, Wang J and Zou H: S100A9 promotes human lung fibroblast cells activation through receptor for advanced glycation end-product-mediated extracellular-regulated kinase $1 / 2$, mitogen-activated protein-kinase and nuclear factor- $\mathrm{kB}$-dependent pathways. Clin Exp Immunol 173: 523-535, 2013.

22. Ghavami S, Rashedi I, Dattilo BM, Eshraghi M, Chazin WJ, Hashemi M, Wesselborg S, Kerkhoff C and Los M: S100A8/A9 at low concentration promotes tumor cell growth via RAGE ligation and MAP kinase-dependent pathway. J Leukoc Biol 83: 1484-1492, 2008.

23. Owens CD, Gasper WJ, Rahman AS and Conte MS: Vein graft failure. J Vasc Surg 61: 203-216, 2015.

24. Jaffe EA, Nachman RL, Becker CG and Minick CR: Culture of human endothelial cells derived from umbilical veins. Identification by morphologic and immunologic criteria. J Clin Invest 52: 2745-2756, 1973.

25. Livak KJ and Schmittgen TD: Analysis of relative gene expression data using real-time quantitative PCR and the 2(-Delta Delta C(T)) method. Methods 25: 402-408, 2001.

26. Wang Q, Wan L, Liu L and Liu J: Role of the mTOR signalling pathway in experimental rabbit vein grafts. Heart Lung Circ 25: 1124-1132, 2016.

27. Ziegler ME, Hatch MM, Wu N, Muawad SA and Hughes CC: mTORC2 mediates CXCL12-induced angiogenesis. Angiogenesis 19: 359-371, 2016.

28. Lieberthal $\mathrm{W}$ and Levine JS: Mammalian target of rapamycin and the kidney. I. The signaling pathway. Am J Physiol Renal Physiol 303: F1-F10, 2012.

29. Wang S, Amato KR, Song W, Youngblood V, Lee K, Boothby M, Brantley-Sieders DM and Chen J: Regulation of endothelial cell proliferation and vascular assembly through distinct mTORC2 signaling pathways. Mol Cell Biol 35: 1299-1313, 2015. 
30. Tandon M, Chen $\mathrm{Z}$ and Pratap J: Runx2 activates PI3K/Akt signaling via mTORC2 regulation in invasive breast cancer cells. Breast Cancer Res 16: R16, 2014.

31. Li X, Sun Y, Huang S, Chen Y, Chen X, Li M, Si X, He X, Zheng H, Zhong L, et al: Inhibition of AZIN2-sv induces neovascularization and improves prognosis after myocardial infarction by blocking ubiquitin-dependent talin1 degradation and activating the Akt pathway. EBioMedicine 39: 69-82, 2019.

32. Lipton JO and Sahin M: The neurology of mTOR. Neuron 84: 275-291, 2014

33. Yan SF, Ramasamy R and Schmidt AM: The RAGE axis: A fundamental mechanism signaling danger to the vulnerable vasculature. Circ Res 106: 842-853, 2010.

34. Palanissami G and Paul SFD: RAGE and its ligands: Molecular interplay between glycation, inflammation, and hallmarks of cancer-a review. Horm Cancer 9: 295-325, 2018.

35. Yamagishi SI and Matsui T: Role of ligands of receptor for advanced glycation end products (RAGE) in peripheral artery disease. Rejuvenation Res 21: 456-463, 2018.

36. Pruenster M, Vogl T, Roth J and Sperandio M: S100A8/A9: From basic science to clinical application. Pharmacol Ther 167: 120-131, 2016.

37. Roth J, Vogl T, Sorg C and Sunderkötter C: Phagocyte-specific S100 proteins: A novel group of proinflammatory molecules. Trends Immunol 24: 155-158, 2003.

38. Kang R, Tang D, Schapiro NE, Livesey KM, Farkas A, Loughran P, Bierhaus A, Lotze MT and Zeh HJ: The receptor for advanced glycation end products (RAGE) sustains autophagy and limits apoptosis, promoting pancreatic tumor cell survival. Cell Death Differ 17: 666-676, 2010.
39. Hou X, Hu Z, Xu H, Xu J, Zhang S, Zhong Y, He X and Wang N: Advanced glycation endproducts trigger autophagy in cadiomyocyte via RAGE/PI3K/AKT/mTOR pathway. Cardiovase Diabetol 13: 78, 2014

40. Chen J, Zhao D, Zhu M, Zhang M, Hou X, Ding W, Sun S, Bu W, Feng L, Ma S and Jia X: Paeoniflorin ameliorates AGEs-induced mesangial cell injury throughinhibiting RAGE/mTOR/autophagy pathway. Biomed Pharmacother 89: 1362-1369, 2017.

41. Li W, Petrimpol M, Molle KD, Hall MN, Battegay EJ and Humar R: Hypoxia-induced endothelial proliferation requires both mTORC1 and mTORC2. Circ Res 100: 79-87, 2007.

42. Sarbassov DD, Ali SM, Sengupta S, Sheen JH, Hsu PP, Bagley AF, Markhard AL and Sabatini DM: Prolonged rapamycin treatment inhibits mTORC2 assembly and Akt/PKB. Mol Cell 22: 159-168, 2006.

43. Yi T, Fogal B, Hao Z, Tobiasova Z, Wang C, Rao DA, Al-Lamki RS, Kirkiles-Smith NC, Kulkarni S, Bradley JR, et al: Reperfusion injury intensifies the adaptive human $\mathrm{T}$ cell alloresponse in a human-mouse chimeric artery model. Arterioscler Thromb Vasc Biol 32: 353-360, 2011.

(i) (5) This work is licensed under a Creative Commons Attribution-NonCommercial-NoDerivatives 4.0 International (CC BY-NC-ND 4.0) License. 